\title{
A comparative proteomic study identified calreticulin and prohibitin up-regulated in adrenocortical carcinomas
}

Ming-shan Yang ${ }^{1 *}$, Huan-sheng Wang ${ }^{1}$, Bao-sheng Wang ${ }^{1}$, Wan-hu Li ${ }^{1}$, Zeng-fen Pang ${ }^{1}$, Ben-kui Zou' ${ }^{1}$ Xin Zhang ${ }^{1}$, Xue-tao Shi ${ }^{1}$, Dian-bin $\mathrm{Mu}^{2}$, De-xian Zhang ${ }^{2}$, Yong-sheng Gao ${ }^{2}$, Xiao-wen Sun ${ }^{3}$ and Shu-jie Xia ${ }^{3}$

\begin{abstract}
Background: Identifying novel tumor biomarkers to develop more effective diagnostic and therapeutic strategies for patients with ACC is urgently needed. The aim of the study was to compare the proteomic profiles between adrenocortical carcinomas (ACC) and normal adrenocortical tissues in order to identify novel potential biomarkers for ACC.

Methods: The protein samples from 12 ACC tissues and their paired adjacent normal adrenocortical tissues were profiled with two-dimensional electrophoresis; and differentially expressed proteins were identified by mass spectrometry. Expression patterns of three differently expressed proteins calreticulin, prohibitin and HSP60 in ACC, adrenocortical adenomas (ACA) and normal adrenocortical tissues were further validated by immunohistochemistry.

Results: In our proteomic study, we identified 20 up-regulated and 9 down-regulated proteins in ACC tissues compared with paired normal controls. Most of the up-regulated proteins were focused in protein binding and oxidoreductase activity in Gene Ontology (GO) molecular function classification. By immunohistochemistry, two biomarkers calreticulin and prohibitin were validated to be overexpressed in ACC compared with adrenocortical adenomas (ACA) and normal tissues, but also calreticulin overexpression was significantly associated with tumor stages of ACC.
\end{abstract}

Conclusion: For the first time, calreticulin and prohibitin were identified to be novel candidate biomarkers for ACC, and their roles during ACC carcinogenesis and clinical significance deserves further investigation.

Virtual slides: The virtual slides for this article can be found here: http://www.diagnosticpathology.diagnomx.eu/vs/ 1897372598927465

Keywords: Adrenocortical carcinomas, Proteomics, Tumor marker, Calreticulin, Prohibitin

\section{Background}

Adrenocortical carcinomas (ACC) is an extremely rare malignancy, accounting for $0.2 \%$ of cancer deaths annually in the world [1]. Most of ACC are carcinomatous, an extremely minor proportion of ACC tumors are characterized by the presence sarcomatous components [2]. Recently, a couple of molecular pathways such as Wnt/ $\beta$-catenin signaling have been found to be involved in the carcinogenesis of ACC [3]. However, for the lack of

\footnotetext{
* Correspondence: sdyangmingshan@163.com

'Department of Urology, Shandong Tumor Hospital, 440 Jiyan Road, Jinan 250117, Shandong Province, China

Full list of author information is available at the end of the article
}

early detection markers and effective treatments, ACC patients, especially advanced-stage patients still have a poor prognosis [4].

Several recent studies have identified a panel of novel biomarkers or potential targets for ACC. For example, Sbiera et al. [5] found that survivin overexpression was associated with a poor prognosis for ACC patients, and targeting survivin might be an interesting new therapeutic approach for ACC. Gaujoux S, et al. [6] confirmed that the presence of $\beta$-catenin nuclear staining is an independent prognostic factor of overall and disease-free survival in patients with resected primary ACC. Duregon et al. [7] suggest that detection of steroidogenic factor 1 (SF-1)

\section{Biomed Central}


could be a novel prognostic marker in adrenocortical cancer. Insulin growth factor type 2 has been demonstrated consistently overexpressed in ACC, and targeting its receptor IGF1R has shown encouraging treatment potential [8]. However, candidate biomarkers for ACC are relatively limited compared with other cancer types. Therefore, there is still an urgent need to identify novel tumor biomarkers to develop more effective diagnostic and therapeutic strategies for patients with ACC.

The comparative proteomic strategies provide useful tools in identifying novel biomarkers for multiple cancers. According to our knowledge, until now, there is still no proteomic study reported on ACC samples. In this study, we compare the proteomic profiles of ACC tissues and their paired normal adrenocortical tissues by two-dimensional electrophoresis (2-DE) and tandem mass spectrometry. A panel of proteins aberrantly expressed in ACC tissues were identified, and part of them were further validated by immunohistochemistry in a larger cohort of samples.

\section{Materials and methods Samples}

For proteomic research, a total of 12 primary ACC tumor tissues and their paired adjacent normal adrenocortical tissues were obtained from patients underwent resective operation at Shandong Tumor Hospital, China. For it is hard to obtain normal healthy adrenocortical tissues, we adopted normal adjacent adrenocortical tissues as a control of ACC in our proteomic studies. Fresh ACC tissue (3-5 $\mathrm{mm}$ in diameter) were obtained from the core part of cancer tissues without necrosis, and grossly normal adjacent tissues were taken from the resection margin of ACC tumors. Resected fresh tissues were first snap-frozen in liquid nitrogen, and stored at $-80^{\circ} \mathrm{C}$ until use. For immunohistochemistry validation study, a total of 39 ACC and paired normal adrenocortical tissues, and 31 benign adrenocortical adenomas (ACA) were also obtained from Shandong Tumor Hospital. All the samples were histologically confirmed by two independent pathologists (D Mu and De Zhang). The study was started upon approved by the ethical committee of our institution, and samples were obtained with informed consent.

\section{Two dimensional electrophoresis (2-DE)}

Frozen ACC and normal adjacent adrenocortical tissues were first homogenized using a sample grinding kit (GE Healthcare) with a lysis buffer (7 M urea, thiourea $2 \mathrm{M}$, 2\% CHAPS, 18 mM DTT, 1 mM PMSF, 0.5\% IPG buffer $\mathrm{pH} 3 \sim 10 \mathrm{NL}$ ), and then the extracts were centrifuged at $12,000 \mathrm{~g}, 4^{\circ} \mathrm{C}$, for $1 \mathrm{hr}$. After the centrifugation, the supernatants were collected for 2-DE analysis. The protein concentration was determined using a 2D Quant kit (GE Healthcare).
We adopted a "sample pool" strategy in the comparative proteomic study as described previously [9]. Equal amount $500 \mu \mathrm{g}$ of proteins extracted from ACC and normal adrenocortical tissues were pooled respectively, and diluted with rehydration buffer (8 M urea, 2\% CHAPS, 0.5\% IPG buffer, $40 \mathrm{mM}$ DTT) for isoelectric focusing. After isoelectric focusing, the strips were first equilibrated with $130 \mathrm{mM}$ DTT in equilibration buffer (6 M urea, 30\% glycerol, 2\% SDS, $50 \mathrm{mM}$ Tris- $\mathrm{HCl}, \mathrm{pH}$ 8.8), and then with $135 \mathrm{mM}$ iodoacetamide in the same buffer. SDS polyacrylamide (SDS-Page) was performed with constant power $(17 \mathrm{~W} /$ gel $)$ at $20^{\circ} \mathrm{C}$ on an Ettan Dalt twelve system (GE healthcare). After the 2-DE, the gels were stained with Coomassie blue R350 and images were scanned for data analysis using Imagemaster 5.0 software package (GE healthcare).

\section{In-gel digestion and mass spectrometry identification}

The gel pieces were first destained with $25 \mathrm{mM}$ $\mathrm{NH}_{4} \mathrm{CO}_{3} / 50 \% \mathrm{ACN}$ for $30 \mathrm{~min}$, and dehydrated in $100 \%$ $\mathrm{ACN}$ for $10 \mathrm{~min}$, and were then digested in $20 \mathrm{ng} / \mu \mathrm{L}$ sequencing grade-modified trypsin (Promega) overnight at $37^{\circ} \mathrm{C}$. After extracted with $5 \% \mathrm{TFA} / 50 \% \mathrm{ACN}$, the peptides were resuspended in $3 \mu \mathrm{L}$ of $0.1 \%$ TFA for mass spectrometry analysis. Protein identification was performed on 4700 Proteomic Analyzer MALDI-TOF-TOF mass spectrometer (Applied Biosystems) in a reflective mode. All mass spectrometry data were searched using the MASCOT search engine against a human subset of the Swiss-Prot database.

\section{Immunohistochemistry}

Three proteins (calreticulin, prohibitin and HSP60) upregulated in ACC identified in the proteomic study were selected for validation in an independent set of samples including $39 \mathrm{ACC}, 31 \mathrm{ACA}$, and 39 normal adrenocortical tissues by immunohistochemistry (IHC). Briefly, after rehydration and deparaffinization, paraffin-embedded tissue slides were processed for antigen retrieval using heating in citrate buffer, and immunohistochemically stained with the rabbit polyclonal antibodies against human calreticulin (1:150 dilution; PTG-Lab) and prohibitin (1:150 dilution; PTG-Lab) and heat shock protein 60 (HSP60) (1:100 dilution; PTG-Lab). All these antibodies were widely used in IHC staining, and their specificity has been confirmed in many previous studies. Visualization was performed using a SP kit (Maixin-Bio, Fujian, China). For the negative controls, the primary antibody was replaced by rabbit IgG.

A semi-quantitative $\mathrm{H}$ score method was used to evaluate the results of IHC as described previously within minor modification [10]. Staining intensity was quantified using the image analysis program Leica Qwin V3, and were graded to four-scale (0-3), while the percentages of 
positive cells were scored into four-scale $(0$, no positive cells; $1,1 \%-33 \%$ positive cells; $2,34 \%-66 \%$; and 3 , $67 \%-100 \%)$. H score (ranging from 0 to 9 ) was calculated by multiplying staining intensity and the percentage of positive cells. The median $\mathrm{H}$-score was used as a cut-off for classify low (< median $\mathrm{H}$-score) and high ( $\geq$ median $\mathrm{H}$-score) expression of each markers.

\section{Statistics}

For proteomic study, spots with intensity changes greater than 2.0-fold were considered as differently expressed spots, and were excised from gels for mass spectrometry analysis. Gene Ontolgoy (GO) analysis was performed using MAS (Molecular Annotation System) 2.0 software (CapitalBio, China). For immunohistochemical results, the difference in $\mathrm{H}$ scores of ACC, ACA, and normal controls were compared with Mann-Whitney $t$ test, and the correlation between biomarkers with the clinicopathological traits of ACC patients was evaluated with Chi-square or Student $t$ test as appropriate. $\mathrm{P}$ value less than 0.05 was considered statistically significant.

\section{Results}

\section{Comparative proteomic profiling between ACC and} adjacent normal adrenocortical tissues

The 2-DE analyses were repeated in three replicas to guarantee the reproducibility of the results. As seen in Figure 1, representative gel images were selected for comparative proteomic analyses of ACC and their normal controls. According to the criteria established, spots with two fold variation between the two groups were defined as differentially expressed proteins. A total of 29 differentially expressed spots were successfully identified by mass spectrometry. Twenty proteins were identified as being up-regulated in ACC samples, compared with their corresponding proteins in normal adrenocortical tissues, while 9 proteins were identified to be downregulated. The details of differently expressed proteins were summarized in Table 1.

\section{Gene Ontology (GO) analysis on the differently expressed} proteins identified in proteomic study

As seen in Table 2, GO analysis on molecular function revealed that up-regulated proteins in ACC samples were enriched most in protein binding (Secretogranin-1, prelamin $\mathrm{A} / \mathrm{C}$, keratin 10 , actin cytoplasmic 1 , glutathione S-transferase $\mathrm{P}$, elongation factor 1-beta, peroxiredoxin-1) and oxidoreductase activity (retinal dehydrogenase 1, peroxiredoxin-1, peroxiredoxin-2, aflatoxin B1 aldehyde reductase member 3 ).

\section{Expression of calreticulin, prohibitin and HSP60 in ACC, ACA and normal adrenocortical tissues by immunohistochemistry}

Three differentially expressed proteins, calreticulin, prohibitin and heat shock protein 60 (HSP60), which had not been reported in previous studies on ACC samples, were selected to be validated in a larger size of samples by immunishotchemistry. As seen in Figure 2, the expression levels ( $\mathrm{H}$ score) of calreticulin, prohibitin and HSP60 were significantly higher in ACC samples than those in normal adrenocortical tissues, which are consistent with the findings in proteomic study. Furthermore, ACC tumors also demonstrated a higher
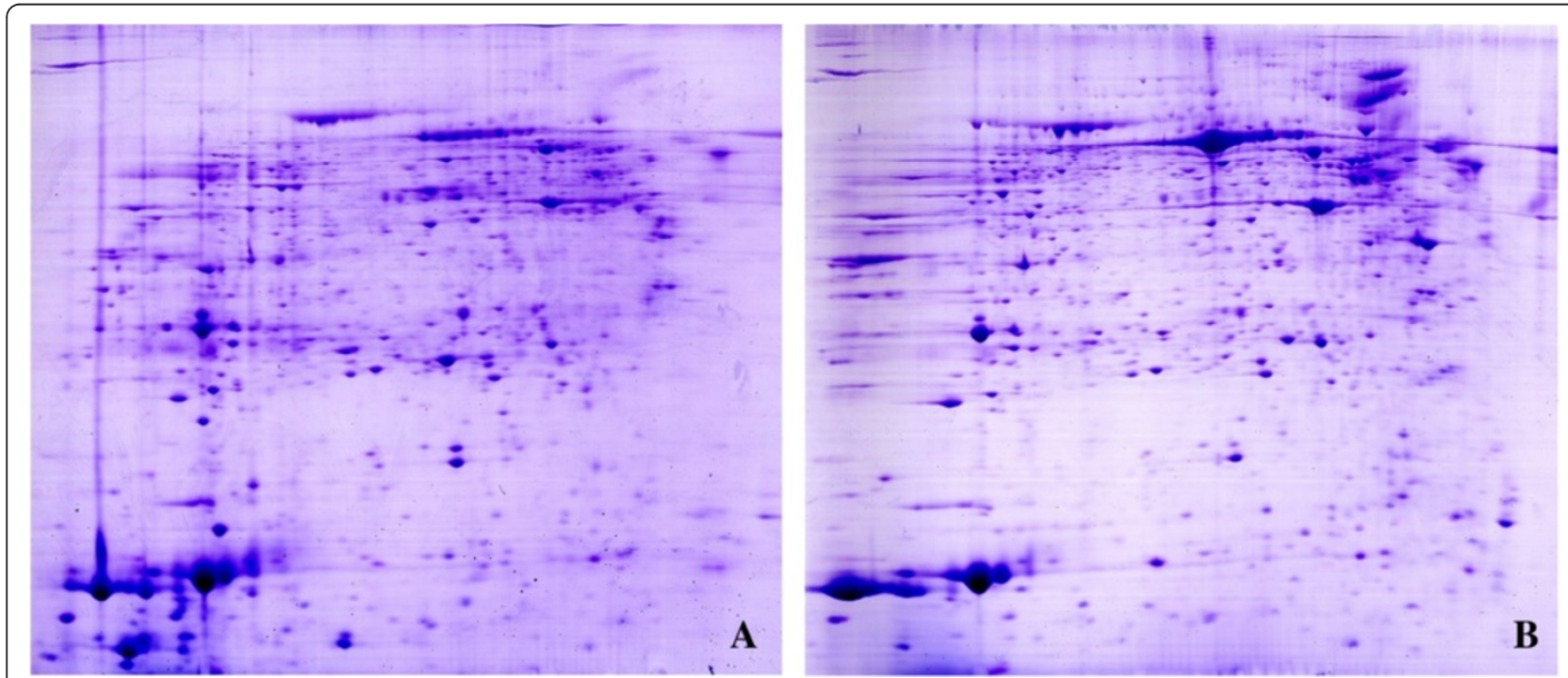

Figure 1 Representative images of two-dimensional electrophoresis (2-DE). 2-DE maps of adrenocortical carcinomas (A) and their paired adjacent normal adrenocortical tissues (B). 
Table 1 Differently expressed proteins between adrenocortical carcinomas and normal adrenocortical tissues in proteomic study

\begin{tabular}{|c|c|c|c|c|c|c|c|}
\hline Protein & $\begin{array}{l}\text { Accession } \\
\text { number }\end{array}$ & $\begin{array}{c}\text { Molecular } \\
\text { weight }\end{array}$ & pl & $\begin{array}{c}\text { Number of matched } \\
\text { peptides }\end{array}$ & $\begin{array}{c}\text { Mascot } \\
\text { score }\end{array}$ & $\begin{array}{c}\text { Sequence } \\
\text { coverage } \%\end{array}$ & Fold \\
\hline Secretogranin-1 & P05060 & 78343 & 5.02 & 24 & 245 & 39 & 2.3 \\
\hline Retinal dehydrogenase 1 & P00352 & 55454 & 6.3 & 9 & 66 & 24 & 3.1 \\
\hline Prelamin-A/C & P02545 & 74379 & 6.57 & 26 & 234 & 37 & 2.2 \\
\hline $\begin{array}{l}\text { Transitional endoplasmic reticulum } \\
\text { ATPase }\end{array}$ & P55072 & 89949 & 5.14 & 31 & 383 & 45 & 4.1 \\
\hline Keratin, type I cytoskeletal 10 & P13645 & 59020 & 5.13 & 11 & 84 & 20 & 2.8 \\
\hline Prohibitin & P35232 & 29843 & 5.57 & 10 & 148 & 51 & 3.8 \\
\hline Transgelin-2 & P37802 & 22548 & 8.41 & 8 & 85 & 49 & 2.2 \\
\hline Selenium-binding protein 1 & Q13228 & 52928 & 5.93 & 8 & 82 & 23 & 2.1 \\
\hline Actin, cytoplasmic 1 & Q96HG5 & 42052 & 5.29 & 11 & 93 & 34 & 4.3 \\
\hline Glutathione S-transferase P & P09211 & 23569 & 5.43 & 12 & 139 & 60 & 2.7 \\
\hline Peroxiredoxin-2 & P32119 & 22049 & 5.66 & 10 & 153 & 47 & 2.4 \\
\hline Rho GDP-dissociation inhibitor 1 & P52565 & 23250 & 5.02 & 11 & 122 & 45 & 2.3 \\
\hline Elongation factor 1-beta & P24534 & 24919 & 4.5 & 10 & 113 & 46 & 3.3 \\
\hline Peroxiredoxin-1 & Q06830 & 22324 & 8.27 & 11 & 165 & 62 & 3.2 \\
\hline 14-3-3 protein epsilon & Q7M4R4 & 29326 & 4.63 & 11 & 111 & 41 & 5.1 \\
\hline 60 kDa heat shock protein & P10809 & 61187 & 5.7 & 18 & 222 & 40 & 4.3 \\
\hline $\begin{array}{l}\text { ATP synthase subunit d, } \\
\text { mitochondrial }\end{array}$ & O75947 & 18537 & 5.21 & 9 & 119 & 59 & 3.8 \\
\hline Retinal dehydrogenase 1 & P00352 & 55454 & 6.3 & 16 & 189 & 41 & 3.6 \\
\hline Calreticulin & P27797 & 48283 & 4.29 & 13 & 180 & 43 & 5.2 \\
\hline $\begin{array}{l}\text { Aflatoxin B1 aldehyde reductase } \\
\text { member } 3\end{array}$ & O95154 & 37582 & 6.67 & 15 & 148 & 48 & 2.6 \\
\hline T-complex protein 1 subunit beta & P78371 & 57794 & 6.01 & 15 & 140 & 43 & -3.2 \\
\hline Elongation factor Tu, mitochondrial & P49411 & 49852 & 7.26 & 26 & 287 & 61 & -4.1 \\
\hline Protein disulfide-isomerase & P07237 & 57479 & 4.76 & 17 & 171 & 37 & -2.2 \\
\hline Vimentin & Q8N850 & 53676 & 5.06 & 12 & 85 & 33 & -2.0 \\
\hline Serum albumin & Q9P157 & 71317 & 5.92 & 27 & 319 & 54 & -3.7 \\
\hline Peroxiredoxin-2 & P32119 & 22049 & 5.66 & 9 & 152 & 43 & -2.8 \\
\hline Tropomyosin alpha-4 chain & Q9UCS3 & 28619 & 4.67 & 10 & 130 & 34 & -2.5 \\
\hline Proteasome subunit beta type- 2 & P49721 & 22993 & 6.51 & 8 & 106 & 49 & -3.3 \\
\hline Fibrinogen gamma chain & Q9UC63 & 52106 & 5.37 & 8 & 86 & 28 & -3.3 \\
\hline
\end{tabular}

Table 2 Gene Ontology (GO) analysis on up-regulated proteins in proteomics study

\begin{tabular}{lcll}
\hline GO term & Count & p-value & Gene symbol \\
\hline GO:0005515 protein binding & 7 & $2.79 \mathrm{E}-08$ & CHGB;LMNA;KRT10;ACTB;GSTP1;EEF1B2;PRDX1 \\
GO:0016491 oxidoreductase activity & 4 & $2.79 \mathrm{E}-08$ & ALDH1A1;PRDX2;PRDX1;AKR7A3 \\
GO:0051087 chaperone binding & 2 & $4.17 \mathrm{E}-07$ & HSPD1;CALR \\
GO:0016887 ATPase activity & 3 & $4.52 \mathrm{E}-07$ & VCP;HSPD1;ATP5H \\
GO:0051082 unfolded protein binding & 2 & $1.33 \mathrm{E}-05$ & HSPD1;CALR \\
GO:0005524 ATP binding & 3 & $3.47 \mathrm{E}-05$ & VCP;ACTB;HSPD1 \\
\hline
\end{tabular}




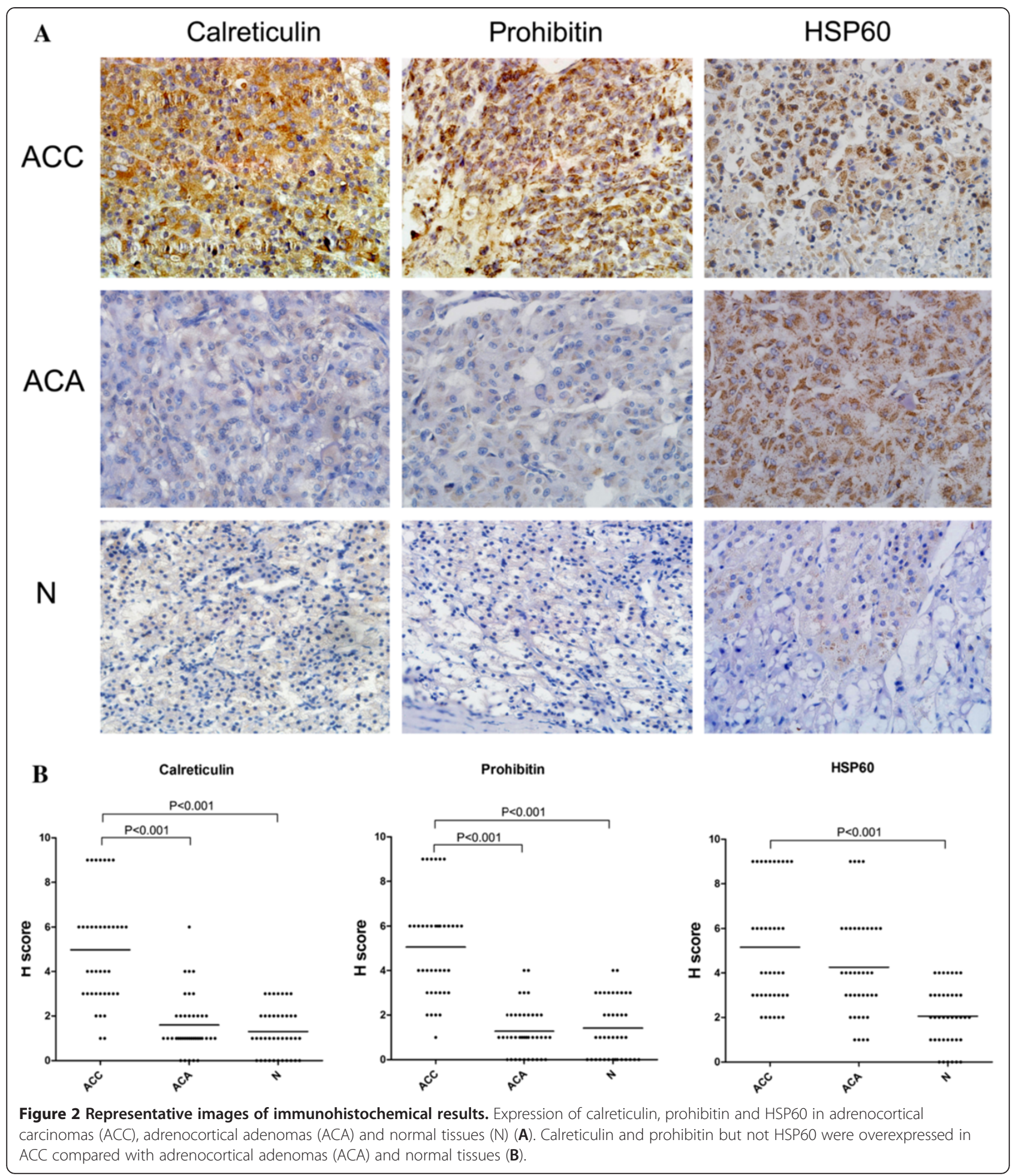

expression level of calreticulin and prohibitin than ACA tumors, but the expression of HSP60 showed no significant difference between malignant and benign adrenocortical tumors. Negative staining with nonspecific rabbit IgG control was documented for each experiment (data not shown).
Association of calreticulin and prohibitin expression with clinicopathological characteristics in ACC

According to the criteria for IHC evaluation, the median $\mathrm{H}$-score of 6 was set as the cut-point to delineate low and high expression for calreticulin and prohibitin. The relationship between calreticulin and prohibitin expre- 
ssion with clinicopathological characteristics of ACC tumors was analyzed. As seen Table 3, no significant difference was observed between calreticulin and prohibitin expression with all the chinicopathological characteristics of ACC tumors, except that calreticulin overexpression was significantly associated with stages in ACC samples. High calreticulin expression was seen more frequently in advanced-stage ACC tumors than in early-stage cases (65.0\% vs. $31.6 \%, \mathrm{P}=0.037)$.

\section{Discussion}

In this study, for the first time, we performed a 2-DE-based proteomic study to compare the protein profiling of ACC and normal adrenocortical tissues. A panel of protein markers were identified to be differently expressed. For only a few samples could be included in traditional proteomic studies, we adopted a "sample pool" strategy to increase the sample size. This strategy could also decrease the sample heterogeneity in some extent. To validate the results of proteomic analysis, we further validate three biomarkers calreticulin, prohibitin and HSP60 in a larger size of samples by immunohistochemestry. These proteins were selected for the following reasons: first, these biomarkers have a relatively high expression level in ACC, compared with normal adrenocortical tissues; secondly, previous studies have indicated that these genes are involved in the malignant progression of multiple cancers, but have not been evaluated in ACC; third, commercial antibodies for immunohistochemistry are available.

Consistent with our proteomic findings, we confirmed calreticulin, prohibitin and HSP60 overexpressed in ACC tumors than normal adrenocortical tissues. It has been suggested that the protein profiling of benign tumors partly resemble their malignant counterparts [11]. A candidate marker elevated in both ACC and ACA would lower their specificity in ACC diagnosis. Therefore, we further compared the expression of calreticulin, prohibitin and HSP60 in ACA and ACC. We found that HSP60 was overexpressed in both ACC and ACA, compared with their normal controls, which would lower its further utility as a candidate biomarker for ACC. Different from HSP60, ACC tissues had significantly higher expression levels of calreticulin and prohibitin than ACA, supporting their utility as specific biomarkers for ACC tumors.

Calreticulin was first identified as a $\mathrm{Ca} 2+$ binding protein, and has been implicated in many cellular functions and pathophysiological process such as cell adhesion, autoimmunity and heat shock [12,13]. Elevated expression of calreticulin has been reported in multiple cancers,

Table 3 Association between calreticulin and prohibitin expression status with clinical charateristics in ACC

\begin{tabular}{|c|c|c|c|c|c|c|c|}
\hline \multirow[t]{2}{*}{ Clinical characteristics } & \multirow[b]{2}{*}{ Total } & \multicolumn{2}{|c|}{ Calreticulin expression } & \multirow[b]{2}{*}{$\mathbf{P}$} & \multicolumn{2}{|c|}{ Prohibitin expression } & \multirow[b]{2}{*}{$\mathbf{P}$} \\
\hline & & $\begin{array}{c}\text { Low } \\
(n=19)\end{array}$ & High $(n=20)$ & & Low $(n=18)$ & High $(n=21)$ & \\
\hline Age $(y$, Mean \pm SD) & & $45 \pm 17.4$ & $37 \pm 14.5$ & 0.129 & $43 \pm 18.6$ & $39 \pm 14.4$ & 0.486 \\
\hline \multicolumn{8}{|l|}{ Gender } \\
\hline Male & 18 & 8 & 10 & 0.621 & 8 & 10 & 0.843 \\
\hline Female & 21 & 11 & 10 & & 10 & 11 & \\
\hline \multicolumn{8}{|l|}{$\begin{array}{l}\text { Tumor } \\
\text { location }\end{array}$} \\
\hline Left & 17 & 7 & 10 & 0.641 & 7 & 10 & 0.150 \\
\hline Right & 19 & 10 & 9 & & 8 & 11 & \\
\hline Bilateral & 3 & 2 & 1 & & 3 & 0 & \\
\hline \multicolumn{8}{|l|}{ Primary tumor size } \\
\hline$<5.0 \mathrm{~cm}$ & 5 & 2 & 3 & & 1 & 4 & \\
\hline $5.0-10.0 \mathrm{~cm}$ & 28 & 16 & 12 & 0.181 & 14 & 14 & 0.454 \\
\hline$>10.0 \mathrm{~cm}$ & 6 & 1 & 5 & & 3 & 3 & \\
\hline \multicolumn{8}{|l|}{ ENSAT stage } \\
\hline $\mid-\|$ & 20 & 13 & 7 & 0.037 & 8 & 12 & 0.429 \\
\hline III- IV & 19 & 6 & 13 & & 10 & 9 & \\
\hline \multicolumn{8}{|c|}{ Hormonal secretory status } \\
\hline Non-functioning tumor & 21 & 12 & 9 & 0.256 & 11 & 10 & 0.399 \\
\hline Functioning tumor & 18 & 7 & 11 & & 7 & 11 & \\
\hline
\end{tabular}


and it is proposed that the upregulation of calreticulin seems to be induced by cellular stress from cancers [14]. Our results indicated that calreticulin correlated to tumor stage of ACC in clinical samples. However, the exact mechanisms for its increases in ACC are as yet undetermined.

Prohibitin has been shown to localize to mitochondria, and has been identified to be up-regulated in many cancers in previous studies [15]. However, experimental data about its role in tumorigenesis is conflicting. Several studies have suggested that prohibitin effects as a tumor suppressor [16], while other data indicated that prohibitin is required for the activation of several central signaling pathways related to carcinogenesis such as RAS-induced RAF-MEK-ERK activation [17]. Our findings supported that prohibitin upregualted in ACC tumors and its roles in ACC carcinogenesis deserves further investigation.

Except above three markers, we also identified other 17 up-regulated proteins in ACC, most of which (such as transitional endoplasmic reticulum ATPase and 14-3-3 protein epsilon) have been demonstrated to be involved in cancer carcinogenesis in other cancers in previous studies [18-20], but have not been reported to be associated with ACC. Therefore, these proteins might also be novel potential candidate markers for ACC, and deserves further investigation in the future.

\section{Conclusions}

In this proteomic study, we identified and validated calreticulin and prohibitin overexpressed in ACC samples compared with their normal and benign counterparts, suggesting that these two markers are novel potential candidate biomarkers for ACCs. We proposed that the molecular mechanisms of calreticulin and prohibitin during ACC carcinogenesis also deserve further investigation in the future.

\section{Competing interests}

The authors have declared no conflicts of interest.

\section{Authors' contribution}

YMS designed the study, performed the experiments, analyzed the data and drafted the manuscript; ZB, ZX, SXT, SXW, XS were responsible for the samples collection; $\mathrm{WH}$ and WB participated in proteomic studies; LW, PZ, GY participated in $\mathrm{HC} ; \mathrm{MD}$ and $\mathrm{ZD}$ were responsible for the histological examination of specimens and $\mathrm{HC}$ results evaluation and score. All the authors read and approved the final manuscript.

\section{Acknowledgements}

This study is supported by the project of Shandong provincial doctor fund (2008BS02017).

\section{Author details}

'Department of Urology, Shandong Tumor Hospital, 440 Jiyan Road, Jinan 250117, Shandong Province, China. ${ }^{2}$ Department of Pathology, Shandong Tumor Hospital, Jinan, Shandong 250117, China. ${ }^{3}$ Department of Urology, Shanghai First Hospital, Shanghai, 10080, China.
Received: 23 February 2013 Accepted: 1 April 2013

Published: 15 April 2013

\section{References}

1. Wajchenberg BL, Albergaria Pereira MA, Medonca BB, Latronico AC, Campos Carneiro P, Alves VA, Zerbini MC, Liberman B, Carlos Gomes G, Kirschner MA: Adrenocortical carcinoma: clinical and laboratory observations. Cancer 2000, 88:711-736.

2. Sasaki K, Desimone M, Rao HR, Huang GJ, Seethala RR: Adrenocortical carcinosarcoma: a case report and review of the literature. Diagn Pathol 2010, 5:51.

3. Tissier F, Cavard C, Groussin L, Perlemoine K, Fumey G, Hagnere AM, Rene-Corail $F$, Jullian E, Gicquel C, Bertagna X, et al: Mutations of beta-catenin in adrenocortical tumors: activation of the Wnt signaling pathway is a frequent event in both benign and malignant adrenocortical tumors. Cancer Res 2005, 65:7622-7627.

4. Vassilopoulou-Sellin R, Schultz PM: Adrenocortical carcinoma. Clinical outcome at the end of the 20th century. Cancer 2001, 92:1113-1121.

5. Sbiera S, Kroiss M, Thamm T, Beyer M, Majidi F, Kuehner D, Wobser M, Becker JC, Adam P, Ronchi C, et al: Survivin in adrenocortical tumors pathophysiological implications and therapeutic potential. Horm Metab Res 2013, 45:137-146.

6. Gaujoux SGS, Fassnacht M, Ragazzon B, Launay P, Libé R, Chokri I, Audebourg A, Royer B, Sbiera S, Vacher-Lavenu MC, Dousset B, Bertagna $X$, Allolio B, Bertherat J, Tissier F: $\beta$-catenin activation is associated with specific clinical and pathologic characteristics and a poor outcome in adrenocortical carcinoma. Clin Cancer Res 2011, 17:9-9.

7. Duregon E, Volante M, Giorcelli J, Terzolo M, Lalli E, Papotti M: Diagnostic and prognostic role of steroidogenic factor 1 in adrenocortical carcinoma: a validation study focusing on clinical and pathologic correlates. Hum Pathol 2012. Epub ahead of print.

8. Demeure MJ, Bussey KJ, Kirschner LS: Targeted therapies for adrenocortical carcinoma: IGF and beyond. Horm Cancer 2011, 2:385-392.

9. Castano EM, Roher AE, Esh CL, Kokjohn TA, Beach T: Comparative proteomics of cerebrospinal fluid in neuropathologically-confirmed Alzheimer's disease and non-demented elderly subjects. Neurol Res 2006, 28:155-163.

10. Yan Y, Skliris GP, Penner C, Chooniedass-Kothari S, Cooper C, Nugent Z, Blanchard A, Watson PH, Myal Y, Murphy LC, Leygue E: Steroid Receptor RNA Activator Protein (SRAP): a potential new prognostic marker for estrogen receptor-positive/node-negative/younger breast cancer patients. Breast Cancer Res 2009, 11:R67.

11. Cui Y, Tian M, Zong M, Teng M, Chen Y, Lu J, Jiang J, Liu X, Han J: Proteomic analysis of pancreatic ductal adenocarcinoma compared with normal adjacent pancreatic tissue and pancreatic benign cystadenoma. Pancreatology 2009, 9:89-98.

12. Qiu Y, Michalak M: Transcriptional control of the calreticulin gene in health and disease. Int J Biochem Cell Biol 2009, 41:531-538.

13. Gold LI, Eggleton P, Sweetwyne MT, Van Duyn LB, Greives MR, Naylor SM, Michalak M, Murphy-Ullrich JE: Calreticulin: non-endoplasmic reticulum functions in physiology and disease. FASEB J 2010, 24:665-683.

14. Ramsamooj P, Notario V, Dritschilo A: Enhanced expression of calreticulin in the nucleus of radioresistant squamous carcinoma cells in response to ionizing radiation. Cancer Res 1995, 55:3016-3021.

15. Guo F, Hiroshima K, Wu D, Satoh M, Abulazi M, Yoshino I, Tomonaga T, Nomura F, Nakatani Y: Prohibitin in squamous cell carcinoma of the lung: its expression and possible clinical significance. Hum Pathol 2012, 43:1282-1288.

16. Wang S, Zhang B, Faller DV: Prohibitin requires Brg-1 and Brm for the repression of E2F and cell growth. EMBO J 2002, 21:3019-3028.

17. Rajalingam K, Wunder C, Brinkmann V, Churin Y, Hekman M, Sievers C, Rapp UR, Rudel T: Prohibitin is required for Ras-induced Raf-MEKERK activation and epithelial cell migration. Nat Cell Biol 2005, 7:837-843.

18. Kim HJ, Kang UB, Lee H, Jung JH, Lee ST, Yu MH, Kim H, Lee C: Profiling of differentially expressed proteins in stage IV colorectal cancers with good and poor outcomes. J Proteomics 2012, 75:2983-2997. 
19. Leal MF, Calcagno DQ, Demachki S, Assumpcao PP, Chammas R, Burbano RR, Smith Mde A: Clinical implication of 14-3-3 epsilon expression in gastric cancer. World J Gastroenterol 2012, 18:1531-1537.

20. Hayashi E, Kuramitsu Y, Fujimoto M, Zhang X, Tanaka T, Uchida K, Fukuda T, Furumoto H, Ueyama Y, Nakamura K: Proteomic profiling of differential display analysis for human oral squamous cell carcinoma: 14-3-3 sigma Protein is upregulated in human oral squamous cell carcinoma and dependent on the differentiation level. Proteomics Clin App/ 2009, 3:1338-1347.

doi:10.1186/1746-1596-8-58

Cite this article as: Yang et al: A comparative proteomic study

identified calreticulin and prohibitin up-regulated in adrenocortical carcinomas. Diagnostic Pathology 2013 8:58.

\section{Submit your next manuscript to BioMed Central and take full advantage of:}

- Convenient online submission

- Thorough peer review

- No space constraints or color figure charges

- Immediate publication on acceptance

- Inclusion in PubMed, CAS, Scopus and Google Scholar

- Research which is freely available for redistribution 